28. Weiss, R. Teich, N., Varmus, H. \& Coffin, J. (eds) RNA Tumor Viruses (Cold Spring Harbor Laboratory, New York, 1982).

29. Kozak, M. Cell 47, 481-483 (1986).

30. Peabody, D. S., Subramani, S. \& Berg, P. Molec. cell. Biol. 6, 2704-2711 (1986)

31. Pelletier, J. \& Sonenberg, N. Nature 334, 320-325 (1988)

32. Felsenstein, K. M. \& Goff, S. P. J. Virol. 62, 2179-2182 (1988).

33. Bernards, A., Rubin, C. M., Westbrook, C. A., Paskind, M. \& Baltimore, D. Molec. cell. Biol. 7, 3231-3236 (1987).

34. Stroehrer, V. L., Jorgensen, E. M. \& Garber, R. L. Molec, cell Biol. 6, 4667-4675 (1986)

35. Gerlich, W. H. \& Robinson, W. S. Cell 21, 801-809 (1980).

36. Ganem, D. \& Varmus, H. E. A. Rev. Biochem. 56, 651-693 (1987).

37. Bond, V. C. \& Wold, B. Molec. cell. Biol. 7, 2286-2293 (1987).

\section{Soluble CD4 blocks the infectivity of diverse strains of HIV and SIV for $T$ cells and monocytes but not for brain and muscle cells}

\author{
Paul R. Clapham, Jonathan N. Weber, Denise Whitby, \\ Kenneth McIntosh§, Angus G. Dalgleish*, \\ Paul J. Maddon†, Keith C. Deen $\ddagger$, \\ Raymond W. Sweet $¥$ \& Robin A. Weiss \\ Chester Beatty Laboratories, Institute of Cancer Research, \\ Fulham Road, London SW3 6JB, UK \\ * MRC Clinical Research Centre, Northwick Park Hospital, \\ Harrow HA1 3UJ, UK \\ $\dagger$ College of Physicians \& Surgeons, Columbia University, \\ New York, New York 10032, USA \\ $\ddagger$ Smith Kline \& French Laboratories, King of Prussia, \\ Pennsylvania 19406, USA
}

The CD4 antigen has been subverted as a receptor by the human and simian immunodeficiency viruses (HIV-1, HIV-2 and SIV) ${ }^{1-4}$. Several groups ${ }^{5-9}$ have reported that recombinant, soluble forms of the CD4 molecule (sCD4) block the infection of T lymphocytes by HIV-1, as CD4 binds the HIV envelope glycoprotein, gp120, with high affinity ${ }^{10,11}$. We now report that sCD4 blocks diverse strains of HIV-1, HIV-2 and SIV, but is less effective for HIV-2. The blocking effect is apparent even after adsorption of virions to CD4 cells. Soluble CD4 prevents HIV infection of T-lymphocytic and myelomonocytic cell lines, but neither SCD4 nor anti-CD4 antibodies inhibit infection of glioma and rhabdomyosarcoma cell lines.

We first investigated the capacity of sCD4 to block infection of diverse strains of HIV-1, HIV-2 and SIV. Table 1 shows that sCD4 preparations blocked the infectivity of each strain tested, but the HIV-2 isolates required 25 -fold higher concentrations of SCD4 than HIV-1 to achieve comparable virus neutralization. In a separate experiment, virus strains were treated with sCD4 and titrated for surviving plaque-forming units (p.f.u.) on MT-4 cells ${ }^{12}$ with the same results. Table 1 also shows that syncytium formation between HIV-producing and uninfected cells ${ }^{1}$ was also inhibited, but was less sensitive to sCD4 than the neutralization of HIV or SIV virions was. This difference may result from the higher viral antigen 'load' present in the cell fusion reaction, which is also less sensitive to most neutralizing antibodies ${ }^{13}$. The relative sensitivity to $\mathrm{SCD} 4$ inhibition of the different virus strains was similar for syncytium formation and HIV titration.

The difference in sensitivity to SCD4 between HIV-1 and HIV-2 may reflect a high concentration of free gp120 in HIV-2 stocks, a higher density of gp 120 on HIV-2 virions, or a higher binding affinity between HIV-1 gp120 and CD4. We used vesicular stomatitis virus (VSV) pseudotypes bearing the envelope glycoproteins of HIV to investigate whether free gp120

8 Permanent address: Division of Infectious Diseases, Children's Hospital, Harvard School of Medicine, Boston, Massachusetts 02115, USA

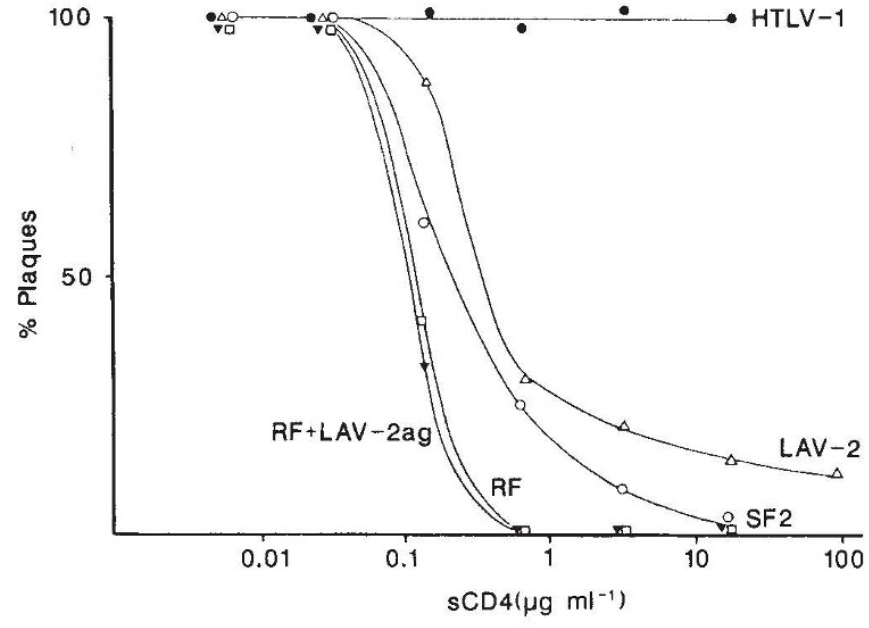

Fig. 1 Inhibition of VSV(HIV) plaque formation by sCD4. VSV pseudotypes bearing the envelope glycoproteins of HIV and HTLV1 were prepared as described ${ }^{1,19,35}$. Pseudotype stocks were diluted to $10^{3}$ p.f.u. $\mathrm{ml}^{-1}$ and were incubated for $1 \mathrm{~h}$ at $37^{\circ} \mathrm{C}$ with sCD4 at the concentrations indicated. The reduction in plaque count was scored after assay on adherent CEM cells ${ }^{1}$. HTLV-1 was the PL strain $^{35}$, LAV-2 $2_{\text {ROD }}$ represented HIV-2, HTLV-IIIRF (RF) and SF2 (ARV-2) represented HIV-1 strains. Undiluted LAV- $2_{R O D}$ supernatant medium (LAV-2 ag) was added to VSV(RF) to test the effect of excess HIV-2 antigen on plaque inhibition by SCD4.

competed with sCD4 neutralization of virions. VSV(HIV) pseudotypes depend on CD4 surface receptors for binding to and entry into host cells ${ }^{1}$. Once inside the cell, however, the pseudotype replicates as VSV, providing a simple plaque assay for viral antigen-cell receptor interactions.

Figure 1 shows that sCD4 was effective in neutralizing both HIV-1 and HIV-2 pseudotypes. The pseudotype of the HIV-1 strain (HTLV-IIIRF) however was more sensitive to SCD4 than the HIV-2 strain tested (LAV-2), and a second HIV-1 strain (SF2, formerly known as ARV-2) was intermediate. SF-2 represents an isolate that is unusually sensitive to antibody neutralization by human sera ${ }^{13}$, and it may react with sCD4 differently from other HIV-1 strains. The $80 \%$ blocking titres of sCD4 for VSV(HIV) pseudotypes were similar to those for HIV infectivity, being approximately $0.3 \mu \mathrm{g} \mathrm{ml}^{-1}$ for VSV(HTLV-IIIRF) and $5 \mu \mathrm{g} \mathrm{ml}^{-1}$ for VSV(LAV-2). As a control for the specificity of SCD4 neutralization, VSV(HTLV-1) pseudotypes were similarly reacted with sCD4 and were not inhibited at any concentration.

Evidence that the observed difference in SCD4 sensitivity between HIV-1 and HIV-2 is not related to soluble gp120 was obtained from a competition experiment in which supernatant medium from an LAV-2 releasing culture was added to VSV(HIV-1) before sCD4 treatment. The HIV-2 containing medium should have no effect on the VSV(HIV) plaque count, but should compete with VSV(HIV) particles for binding SCD4. LAV-2 supernatants were added to VSV(HTLV-IIIRF) at a concentration that required at least $40 \mu \mathrm{g} \mathrm{ml}^{-1} \mathrm{sCD} 4$ for its infectivity to be inhibited. Despite this 'overload' of HIV-2 antigen, there was no reduction in sensitivity of VSV(HTLVIIIRF) to sCD4 inhibition (Fig. 1). Addition of HIV-1 supernatant had no effect on VSV(HIV) inhibition either (data not shown).

We next investigated whether SCD4 would inhibit HIV after virions had bound to cellular CD4 receptors. Serial dilutions of HIV-1 were treated with SCD4 either before adsorption or one hour after adsorption to T cells. The results (Table 2) demonstrate the potential of SCD4 to block HIV post-adsorption, albeit some 50 -fold less efficiently than if added to HIV before adsorption. The blocking effect indicates that even after binding to 
Table 1 Soluble CD4 inhibition of infection and syncytium formation by HIV-1, HIV-2 and SIV strains

\begin{tabular}{|c|c|c|c|c|}
\hline \multirow[b]{2}{*}{ Virus } & & \multicolumn{3}{|c|}{ Inhibition titre of $\mathrm{sCD} 4\left(\mu \mathrm{g} \mathrm{ml}^{-1}\right)$} \\
\hline & & $\begin{array}{l}\text { Infection } \\
\text { TCID }\end{array}$ & $\begin{array}{l}\text { Plaque } \\
\text { assay }\end{array}$ & $\begin{array}{l}\text { Syncytium } \\
\text { formation }\end{array}$ \\
\hline \multirow[t]{4}{*}{ HIV-1 } & HTLV-IIIB & 0.3 & 0.3 & 1.5 \\
\hline & HTLV-IIIRF & 0.3 & 0.3 & 1.5 \\
\hline & SF33 & 0.12 & 0.12 & 0.6 \\
\hline & CBL4 & 0.3 & ND & 1.5 \\
\hline \multirow[t]{2}{*}{ HIV-2 } & LAV-2 $2_{\text {ROD }}$ & 7.6 & 7.6 & 38 \\
\hline & CBL20 & 7.6 & 7.6 & 38 \\
\hline \multirow[t]{3}{*}{ SIV } & SMM (mangabey) & 0.6 & ND & 7.6 \\
\hline & MAC (macaque) & 0.6 & ND & 7.6 \\
\hline & AGM (green monkey) & 0.6 & ND & 7.6 \\
\hline
\end{tabular}

Soluble CD4 representing the whole of the extracellular domain was prepared as previously described ${ }^{8}$. For infection inhibition (neutralization) assays, serial dilutions of sCD4 were incubated at $37^{\circ} \mathrm{C}$ for one hour with 1,000 T-cell infectious doses (TCID) of HIV or SIV. The surviving infectious virus was titrated by plating dilutions of the sCD4treated virus on $\mathrm{C} 8166 \mathrm{~T}$ cells and recording virus replication by the appearance of syncytia and reverse transcriptase activity 48-72 hours later ${ }^{19}$. Virus treated with sCD4 was also titrated in the MT4 cell HIV plaque assay ${ }^{12}$. For syncytium formation, chronically infected $\mathrm{H} 9$ cells were mixed with uninfected C8166 indicator cells and multinucleated syncytia were counted after incubation overnight ${ }^{19}$. The concentration of sCD4 neutralizing over $80 \%$ of TCID and p.f.u., and causing $80 \%$ inhibition of syncytium formation are tabulated for each virus strain. ND, not determined.

cellular CD4, HIV infection can be inhibited by the competing soluble homologue, before internalization by a $\mathrm{pH}$-independent fusion process ${ }^{14-16}$.

HIV infection of T-lymphocytic ${ }^{1,2,17}$ and monocytic ${ }^{18,19}$ cells can be blocked by preincubating the cells with certain anti-CD4 monoclonal and polyclonal antibodies. Other cell types, notably glioma cell lines ${ }^{20-22}$ and RD cells ${ }^{23}$, can also be infected with high titres of HIV-1. HIV-susceptible glial cell lines, such as U138, are negative for CD4 surface expression by immunofluorescence, but express low levels of CD4 mRNA. (J.N.W., unpublished observations). Preliminary experiments indicated that anti-CD4 antibodies did not inhibit HIV infection. The low density of CD4 expression on glial cells might prevent anti-CD4 attaching with sufficient avidity to compete with HIV binding. By using sCD4 as an inhibitory reagent binding to the virion glycoproteins, gp120, rather than to the cellular receptor molecule, the question of whether CD4 is required for infection of these cells can be addressed more clearly.

Table 3 shows that U138 astroglioma cells, but not U87 astroglioma cells, can be infected with the HTLV-IIIRF strain of HIV-1. The TE671 cell line can also be infected with HIV ${ }^{20}$. This line was thought to be derived from a human medulloblastoma $^{24}$, but is now known to be the RD rhabdomyosarcoma cell line $^{25}$. A relatively high input of virus required for U138 and $\mathrm{RD}$ cell infection ( $>10^{3} \mathrm{~T}$-lymphocyte infectious units), and the infection is only weakly productive. Not enough virions are released into the supernatant medium of infected U138 or RD cultures to register as positive in reverse transcriptase or p24 antigen assays, and it seems that only a small proportion of cells contain HIV antigens or proviral DNA ${ }^{20-22}$. Virus can readily be rescued by cocultivation with a fully permissive $T$-cell line however, such as $\mathrm{C} 8166$ or by transfer of the supernatant medium of infected glioma cell cultures to $\mathrm{C} 8166$ cells. Incubation of HIV-1 with SCD4 before plating failed to block infection of brain or muscle cell lines at $18 \mu \mathrm{g} \mathrm{ml}^{-1}$ or even $180 \mu \mathrm{g} \mathrm{ml}^{-1}$. In a parallel experiment, monoclonal antibodies reacting to CD4 antigen (Leu3a, F101-5) efficiently blocked HIV infection of $\mathrm{CD}^{+}$lymphocytic and monocytic cells but also failed to block
Table 2 Reduction of HIV-1 infection by sCD4 after adsorption of virus to T-lymphocytes scored by syncytial focus assay

\begin{tabular}{cccc}
$\begin{array}{c}\text { Virus } \\
\text { dilution }\end{array}$ & $\begin{array}{c}\text { No. } \\
\text { sCD4 }\end{array}$ & $\begin{array}{c}\text { sCD4 added } \\
\text { before HIV } \\
\text { adsorption }\end{array}$ & $\begin{array}{c}\text { sCD4 added } \\
\text { after HIV } \\
\text { adsorption }\end{array}$ \\
$10^{\circ}$ & con, con & 1,2 & 105,85 \\
$10^{-1}$ & 203,240 & 0,0 & 10,13 \\
$10^{-2}$ & 25,41 & 0,0 & 3,1 \\
$10^{-3}$ & 4,2 & 0,0 & 0,0 \\
\hline
\end{tabular}

HIV-1 (HTLV-IIIRF) was titrated by a syncytial focus assay as follows: C 8166 cells $\left(10^{6}\right.$ cells in $0.5 \mathrm{ml} \mathrm{RPMI} / 1640$ medium with $10 \%$ fetal calf serum) were plated into $12-\mathrm{mm}$ tissue culture wells in 24-well plate wells (Nunclon, Denmark) coated with $50 \mu \mathrm{g} \mathrm{ml}^{-1}$ poly-L-lysine to form a monolayer. After $20 \mathrm{~min}$ at room temperature, appropriate virus dilutions were added and adsorbed for $1 \mathrm{~h}$ on ice. The monolayers were washed in culture medium to remove unabsorbed virus and were incubated in medium for $1 \mathrm{~h}$, washed again, and overlaid with $1 \mathrm{ml}$ culture medium containing $0.9 \%$ molten Sea Plaque agarose (FMC Bioproducts). After $42 \mathrm{~h}$ incubation at $37^{\circ} \mathrm{C}, 1 \mathrm{ml}$ agarose containing $0.0032 \%$ Neutral Red was added and at $48 \mathrm{~h}$ discrete focal areas of syncytia were counted by low power magnification $(\times 20)$. The linear dose-response of syncytial foci in the absence of sCD4 indicated that each focus resulted from a single infectious unit of HIV and the focus titre correlated well with HIV titration by end-point dilution on C8166 cells in suspension $\left(\mathrm{TCID}_{50}\right)$. To measure the inhibitory effect of $\mathrm{sCD} 4$, $40 \mu \mathrm{g} \mathrm{ml}^{-1}$ protein was added to serially diluted HIV for $1 \mathrm{~h}$ on ice in culture medium before adsorption, or was added to the washed cell monolayer on ice following virus adsorption. The numbers represent focus counts of duplicate wells for each sCD4 treatment and virus dilution. Con, confluent syncytia.

infection of brain tumour cells. In contrast, a human serum containing antibodies to gp120, gp41 and gag antigens neutralized HIV for all cell types (Table 3 ). It is most unlikely that input virus has been carried over in the brain cell cultures, in view of the serial passage and trypsinization of these cells, and that the resistant U87 glial cell line did not yield rescued virus upon subsequent cocultivation with T cells (Table 3 ). Moreover, proviral DNA has been detected after HIV infection of these cell types ${ }^{20,21}$. We therefore conclude that HIV infects glial and muscle cells in a way that is not mediated by CD4.

Soluble CD4 is under investigation as a therapeutic agent in HIV-infected subjects. One concern is that sCD4 might itself be immunosuppressive, reacting in vivo with the apparent natural ligand for $\mathrm{CD} 4$, the major histocompatibility complex $(\mathrm{MHC})$ class II antigens ${ }^{4,26}$. Little or no effect of sCD4 on class II-restricted T-cell interactions is seen in vitro however ${ }^{7}$. The primary recognition site on CD4 for gp120 is close to the Leu3a antigenic epitope $\mathrm{e}^{4,27}$ and has been mapped to the N-terminal immunoglobulin V-like domain ${ }^{28,29}$. An sCD4 fragment or peptide containing this site but which was not involved in immune recognition would be desirable, though the evolutionary conservation among primate species of the gp120/Leu3a site suggests that this epitope may be important for normal functions of the CD4 molecule ${ }^{30}$.

Our results show that neither sCD4 nor Leu3a antibody block infection of certain brain and muscle cell lines. These unexpected results indicate that HIV may not require cell surface CD4, nor perhaps viral gp120, to gain entry to these cells in vitro. It would seem unlikely to depend on an artefactual 'transfection' as described for bacteriophage $e^{31}$ as DEAE-dextran was not used to enhance virion uptake, and the RD/TE671 cultures became infected with an input as low as $0.05 \mathrm{~T}$-cell infectious doses per cell (Table 3). HIV and VSV(HIV) pseudotypes are unable to infect mouse cells expressing human $\mathrm{CD} 4$ or to induce cell fusion although the virions bind to the CD4 molecules ${ }^{32}$. A second membrane molecule may therefore be required for fusion and viral penetration. In view of the relatively low efficiency of infection of glioma and myoblast cells compared to $\mathrm{CD} 4^{+} \mathrm{T}$ 
Table 3 Effect of SCD4 and anti-CD4 antibody on HIV-1 infection of different human cell types

\begin{tabular}{|c|c|c|c|c|c|c|c|c|c|}
\hline \multirow[b]{2}{*}{ Cell type } & \multirow{2}{*}{$\begin{array}{c}\text { Input } \\
\text { HIV (TCID) }\end{array}$} & \multicolumn{2}{|c|}{ Human anti-HIV-1 } & \multicolumn{2}{|c|}{ Leu3a anti-CD4 } & \multicolumn{2}{|c|}{$\mathrm{sCD} 4180 \mu \mathrm{g} \mathrm{ml}^{-1}$} & \multicolumn{2}{|c|}{ Control } \\
\hline & & SF & RF & SF & RT & SF & $\mathrm{RT}$ & SF & RT \\
\hline \multicolumn{10}{|l|}{$\mathrm{T}$ cell } \\
\hline C8166 & $5 \times 10^{3}$ & - & - & - & - & - & - & +++ & 20,000 \\
\hline \multicolumn{10}{|c|}{ Myelomonocyte } \\
\hline \multirow[t]{2}{*}{ U937 } & $5 \times 10^{5}$ & ND & ND & - & - & - & - & $t+t$ & 27,000 \\
\hline & $5 \times 10^{3}$ & - & - & - & - & - & - & $+t+$ & 55,000 \\
\hline \multirow[t]{2}{*}{ HL60 } & $5 \times 10^{5}$ & ND & ND & - & - & - & - & ++ & 49,000 \\
\hline & $5 \times 10^{3}$ & - & - & - & - & - & - & ++ & 9,000 \\
\hline \multicolumn{10}{|l|}{ Glioma } \\
\hline U138 & $5 \times 10^{5}$ & - & - & ++ & 21,000 & ++ & 23,000 & ++ & 23,000 \\
\hline U87 & $5 \times 10^{5}$ & - & - & - & - & - & - & - & - \\
\hline \multicolumn{10}{|l|}{ Muscle } \\
\hline \multirow[t]{2}{*}{ RD/TE671 } & $5 \times 10^{5}$ & - & - & ++ & 18,000 & ++ & 26,000 & ++ & 19,000 \\
\hline & $5 \times 10^{3}$ & - & - & ++ & 9,000 & ++ & 20,000 & ++ & 18,000 \\
\hline
\end{tabular}

HIV-1 (HTLV-IIIRF strain) was incubated with anti-HIV-1 antibody or with sCD4 for $1 \mathrm{~h}$ at $37^{\circ} \mathrm{C}$ before plating on $10^{6}$ cells of the types indicated. Syncytium formation (SF) and reverse transcriptase (RT) activity in the medium was scored 5 days post-infection for the T-cell and myelomonocyte cultures. For the glial and myoblast cultures there were no detectable SF or RT activity as previously described ${ }^{20-23}$. After seven days and two trypsin-mediated passages of the glial and myoblast cells, C8166 cells were added to the cultures, and SF and RT activity was scored 3 days later. Virus production for cells exposed to HIV-1 (not treated with anti-CD4 or sCD4) was also detected after 3 weeks and 6 passages in U138 and RD/TE671 cells, but not U87 cells. The glial cells expressed glial fibrillar acidic protein, confirming their provenance. SF scores: +++ , $>50 \%$ giant syncytial cells in culture;,$++ 10-50 \%$ syncytial cells;,$+ 1-9 \%$ syncytial cells;,- no discernable syncytia. RT scores in c.p.m. acid precipitable $\left[{ }^{3} \mathrm{H}\right]$ thymidine incorporation; $-,<1,000$ c.p.m. ND, not determined.

lymphocytes, HIV infection might occur by gp41-mediated membrane fusion in the absence of specific gp120-CD4 receptor interaction.

It is not clear whether HIV infection of astroglial cells has a role in HIV encephalopathy (as infection is mainly detectable in microglial and endothelial cells ${ }^{33,34}$ ) or whether muscle infection is related to the weight loss and wasting seen in AIDS. Although our results may be restricted to cells in vitro, HIV infection of glial and muscle in the presence of excess sCD4 merits further investigation, given the interest in developing sCD4 as a therapeutic agent.

We thank M. Popovic and R. C. Gallo for providing C8166 cells, HTLV-IIIB and HTLV-IIIRF, J. Levy for SF2 and SF33, L. Montagnier for LAV-2, P. Marx for $\mathrm{SIV}_{\mathrm{SMM}}$, M. Daniel for SIV $_{\text {MAC, M. Hayami for SIV }}$ AGM $_{1}$ K. Nilsson for U87, U138 and U937 cells, M. Stratton for TE671 cells, and J. Zavada for sheep hyperimmune serum against VSV. This study was supported by the MRC, Wellcome Trust and Cancer Research Campaign.

Received 26 August; accepted 8 December 1988.

1. Dalgieish, A. G. et al. Nature 312, 763-766 (1984).

2. Klatzmann, D. et al. Nature 312, 767-768 (1984)

3. Sattentau, Q. J. et al. AIDS 2, 17-21 (1988).

4. Sattentau, Q. J. \& Weiss, R. A. Cell 52, 631-633 (1988)

5. Smith, D. H. et al. Sciences 238, 1704-1707 (1987).

6. Fisher, R. A. et al. Nature 331, 76-78 (1988).

7. Hussey, R. E. et al. Nature 331, 78-81 (1988).

8. Deen, K. C. et al. Nature 331, 82-84 (1988).

9. Traunecker, A., Luke, W. \& Karjalainen, K. Nature 331, 84-86 (1988).

10. McDougal, J. S. et al. Science 231, 382-385 (1986)

11. Lasky, L. A. et al. Cell 50, 975-985 (1987).

12. Harada, S., Koyanagi, Y. \& Yamamoto, N. Science 229, 563-566 (1985).

13. Weiss, R. A. et al. Nature 324, 572-575 (1986).

14. Stein, B. S. et al. Cell 49, 659-668 (1987)

15. McClure, M. O., Marsh, M. \& Weiss, R. A. EMBO J. 7, 513-518 (1988)

16. Maddon, P. J. et al. Cell 54, 865-874 (1988)

17. Sattentau, Q. J., Dalgleish, A. G., Weiss, R. A. \& Beverley, P. C. L. Science 234, 1120-1123 (1986).

18. Åsjö, B. et al. Virology 157, 359-365 (1987)

19. Clapham, P. R. et al. Virology 158, 44-51 (1987)

20. Dewhurst, K. et al. FEBS Lett. 213, 138-143 (1987)

21. Chiodi, F. et al. J. Virol. 61, 1244-1247 (1987).

22. Cheng-Mayer, E. et al. Proc. natn. Acad. Sci. U.S.A. 84, 3526-3530 (1987)

23. Srinivasan, A. et al. Arch. Virol. 99, 21-30 (1988)

4. McAllister, R. M. et al. Int. J. Cancer 20, 206-212 (1977)

5. Stratton, M. R., Reeves, B. R. \& Cooper, C. S. Nature 337, 311-312 (1989).

26. Doyle, C. \& Strominger, J. Nature 330, 256-259 (1987).

27. Chanh, T. C., Dreesman, G. \& Kennedy, R. C. Proc, natn. Acad. Sci. U.S.A. 84, 3891-3895 (1987)

28. Landau, N. R., Warton, M. \& Littman, D. R. Nature 334, 159-162 (1988).

29. Peterson, A. \& Seed, B. Cell 54, 65-72 (1988).
30. McClure, M. O. et al Nature 330, 487-489 (1987).

31. Lowy, I. et al. Cell 22, 817-824 (1980)

32. Maddon, P. J. et al. Cell 47, 333-348 (1986)

33. Koenig, S. et al. Science 233, 1089-1093 (1986).

34. Wiley, C. A., Schrier, R. D., Nelson, J. A., Lampert, P. W. \& Oldstone, M. B. A. Proc. natn Acad. Sci. U.S.A. 83, 7089-7093 (1986).

35. Clapham, P. R., Nagy, K. \& Weiss, R. A. Proc. natn. Acad. Sci. U.S.A. 81, 3083-3086 (1984)

\section{Productive dual infection of human $\mathrm{CD4}^{+} \mathrm{T}$ lymphocytes by HIV-1 and HHV-6}

\author{
Paolo Lusso, Barbara Ensoli, Phillip D. Markham*, \\ Dharam V. Ablashi, S. Zaki Salahuddin, \\ Erwin Tschachler, Flossie Wong-Staal \\ \& Robert C. Gallo
}

Laboratory of Tumor Cell Biology, National Cancer Institute, Bethesda, Maryland 20892, USA

* Department of Cell Biology, Bionetics Research Inc., Rockville, Maryland 20850, USA

Although infection by HIV-1 (refs 1 and 2) has been implicated as the primary cause of AIDS and related disorders ${ }^{3,4}$, cofactorial mechanisms may be involved in the pathogenesis of the disease. For example, several viruses commonly detected in AIDS patients and capable of transactivating the long terminal repeat of HIV-1, such as herpesviruses ${ }^{5-7}$, papovaviruses ${ }^{7}$, adenoviruses ${ }^{8}$ and HTLVI (ref. 9), have been suggested as potential cofactors. Another candidate is human herpesvirus-6 (HHV-6, originally.designated human B-lymphotropic virus) ${ }^{10-12}$, which has not only been identified in most patients with AIDS by virus isolation ${ }^{10,13,14}$, DNA amplification techniques ${ }^{15}$ and serological analysis ${ }^{16}$, but is also predominantly tropic and cytopathic in vitro for $\mathrm{CD4}^{+} \mathrm{T}$ lymphocytes $^{17,18}$. Here we demonstrate that HHV-6 and HIV-1 can productively co-infect individual human $\mathrm{CD}^{+} \mathrm{T}$ lymphocytes, resulting in accelerated HIV-1 expression and cellular death. We also present evidence that HHV-6 transactivates the HIV-1 long terminal repeat (LTR). These observations indicate that HHV-6 might contribute directly or indirectly to the depletion of $\mathrm{CD4}^{+}$ $T$ cells in AIDS. 